\title{
Assessment of DNA damage in Ehlrich carcinoma after treatment with doxorubicin encapsulated in nanoscales thermosensitive liposomes in combination with localized hyperthermia
}

\author{
Monira M. Rageh ${ }^{1}$, Medhat W. Shafaa ${ }^{2}$, Mona R. Elhefnawy ${ }^{2}$ and Mohamed S. El-Nagdy ${ }^{2}$ \\ ${ }^{1}$ Biophysics Department, Faculty of Science, Cairo University, Cairo, Egypt \\ ${ }^{2}$ Physics Department, Faculty of Science, Helwan University, Cairo, Egypt
}

\begin{abstract}
Nanoscales thermosensitive liposomes (TSL) composed of synthetic lipids (dipalmitoylphosphatidylcholine, and distearoylphosphatidylcholine), were used for doxorubicin encapsulation with $70 \%$ encapsulated efficiency. The liposomes were characterized by dynamic light scattering, transmission electron microscopy and turbidity method. Additionally, the liposomes exhibited a significant release of doxorubicin (Dox) by $60 \%$ within $5 \mathrm{~min}$ at $42^{\circ} \mathrm{C}$. To assess the therapeutic efficacy of Dox in combination with hyperthermia, Dox free and encapsulated TSL were administered directly to Ehrlich tumor bearing mice at $1 \mathrm{mg} / \mathrm{kg}$ dose. Immediately after the drug administration, hyperthermia was applied to mention the temperature inside the tumor site at $42^{\circ} \mathrm{C}$ either for $5 \mathrm{~min}$ and $30 \mathrm{~min}$. The results indicate a significant increase in the percent of apoptotic and necrotic cells in the treated group. Moreover, disrupts the integrity and the amount of intact DNA in tumor cells. In conclusion, Dox and hyperthermia may serve as a useful targeted drug delivery system for management of Ehrlich carcinoma.
\end{abstract}

Key words: Thermosensitive liposomes - Hyperthermia - Doxorubicin - Cancer - Comet Assay - DNA

\section{Introduction}

Drug delivery systems have been developed for cancer therapy in an attempt to increase the tumor drug concentration while limiting systemic exposure. Anticancer drug therapy is fraught with systemic toxicities resulting from cytotoxicity to normal cells. Cancer cells share many common features with the normal host cells from which they originate, so finding unique targets against which anticancer drugs can be selectively directed is difficult. Many anticancer drugs have a marginal selectivity for malignant cells because they target the reproductive apparatus in cells having high proliferation rates. However, anticancer drugs having this mechanism of action result in high toxicities against rapidly dividing normal cells. The side effects associated with chemotherapy limit the dose or cumulative doses that can be administered

Correspondence to: Medhat Wahba Shafaa, Physics Department, Faculty of Science, Helwan University, Cairo, Egypt

E-mail: medhatwi@hotmail.com to patients, which can lead to relapse of the tumor and often the development of drug-resistance.

One successful approach has been to use drug carriers like liposomes to alter the pharmacokinetics and bio distribution of anticancer drugs. Liposomes, the phospholipid vesicles, are spherical lipid bilayers capable of entrapping water soluble solutes within an aqueous domains or alternatively lipid molecules within the lipid bilayers. They are biodegradable, biocompatible and non-immunogenic in nature, which makes them ideal drug carrier systems in therapeutics. The efficacy of liposomes as drug delivery systems would be increased dramatically if it were possible to deliver their contents selectively to particular cells or anatomical sites.

Liposomes have been reported to modulate the stability and to improve the pharmacokinetic properties of the encapsulated drug reducing side effects and improving its in vitro and in vivo activity (Wells et al. 2003; Hincu et al. 2007; Porfire et al. 2009). A major goal for many years has been the development of liposomes that can be activated to release their contents only at the targeted site. Thus, it was necessary 
to design better liposomal carriers, such that the liposomes can be triggered to release encapsulated contents. Various triggering mechanisms have been described in literature, including those that rely on changes in local microenvironment such as a decreased $\mathrm{pH}$ and the presence of specific enzymes, as well as the use of externally applied triggers such as light, ultrasound and heat (Chiu et al. 2005).

Upon arrival in the tumor area, heat may also be applied to trigger the release of liposomal drug contents. To achieve this, thermosensitive liposomes are being developed. The formulation of such liposomes is based on pioneering work of Yatvin and Weinstein in the late 1970s (Yatvin et al. 1978), who described the use of liposomes composed of phospholipids that undergo a gel-to-liquid crystalline phase transition at temperatures of around $44^{\circ} \mathrm{C}$, a process which, in the absence of cholesterol in the membrane, causes significant release of liposome-entrapped water soluble compounds.

The use of hyperthermia (HT) has been actively pursued due to several advantages: hyperthermia can increase tumor blood flow and microvascular permeability and the extravasation and accumulation of liposomes in the locally heated tumor. Hyperthermia has been used as an adjuvant therapy in surgery, radiation and chemotherapy. Supra-additive cytotoxic effects may be achieved when hyperthermia is used in combination with several chemotherapeutic agents which can be delivered via liposome encapsulation (Hahn et al. 1975; Dewhirst et al. 1997; Kong et al. 2000; Needham and Dewhirst 2001).

Doxorubicin (Dox) is the first anthracycline antibiotic that was used clinically to fight cancer. The mechanisms of action for this drug at the DNA level are binding DNA effectively by intercalation anthracycline portion, causing DNA damage via the production of free radicals from reactive oxygen species (ROS) and stabilizing the topoisomerase II cleavage complex, which is critical for DNA transcription and replication. As a consequence of these multiple effects, single and double-strand breaks are introduced into the DNA (Cummings et al. 1991). Although a large number of analogues have been synthesized since its discovery in an effort to obtain therapeutic agents with increased activity or reduced toxicity, Dox is still considered as one of the most effective anticancer drugs. Unfortunately its clinical usefulness is often limited due to the high cardiotoxicity of the drug. In an effort to increase the therapeutic usefulness of the drug many different formulations were proposed. Among these, the encapsulation of Dox in liposomes has proved to be an attractive method for reducing the toxicity of the drug (Sadzuka et al. 2003; Papagiannaros et al. 2006).

The present study was aimed to evaluate the DNA damage in Ehlrich carcinoma cells after treatment with Dox encapsulated in nanoscales thermosensitive liposomes (TSL) in combination with localized HT.

\section{Materials and Methods}

\section{Chemicals}

1,2-dipalmitoyl-sn-glycero-3-phosphatidylcholine (DPPC) with molecular weight 734 (99\% pure), 1,2-distearoyl-snglycero-3-phosphocholine (DSPC) with molecular weight 790 (99\% pure), Ethanol 99\%, Triton X100, and Trizma buffer with a molecular weight of 121.1 were purchased from Sigma-Aldrich company (St. Louis, Mo, USA). Doxorubicin hydrochloride with mean molecular weight 579 (Adriblastina ${ }^{\circledR}$ ) was purchased from pharmacia Italia S.P.A, Italy. All other chemicals used in this work were of research grade.

\section{Liposome preparation}

Liposomes were prepared by the thin film hydration method as described previously (Tagami et al. 2011). Briefly, DPPC/ DSPC were mixed in a molar ratio (9:1) then dissolved in $10 \mathrm{ml}$ ethanol in around bottom flask. The liposome mixture was shacked well for a few minutes then a vigorous vortexing took place to assure a complete solvation. The organic solved was removed gradually using a rotary evaporator (Janke\&Kunkel RV05-ST, Germany) under a steam of nitrogen gas in a warm water bath $\left(45^{\circ} \mathrm{C}\right)$ to produce a thin film of lipid. The lipid film was hydrated with $5 \mathrm{ml}$ of $10 \mathrm{mM}$ Trizma buffer ( $\mathrm{pH} \mathrm{7.4)} \mathrm{in} \mathrm{a} \mathrm{water} \mathrm{bath} \mathrm{at} 55^{\circ} \mathrm{C}$ for $10 \mathrm{~min}$ to form multilamellar vesicles (MLV). The MLV was sonicated by a probe sonicator (Homogeneizador, optic ivyMen ${ }^{\circledR}$ system, CY-500, Spain) for $2 \mathrm{~min}$ at $90 \%$ amplitude with a pulse 02:02 to form the small unilamellar vesicles (SUV) as a control (empty) liposomes. Parallel to the control DPPC/DSPC/Dox liposomal sample, hydration of the dry lipid thin film was achieved with $5 \mathrm{ml}$ of Trizma buffer containing Dox (drug to lipid molar ratio $=2: 7$ (Mayer et al. 1990)). The flask was mechanically shaken for $15 \mathrm{~min}$ at $45^{\circ} \mathrm{C}$. The suspension was centrifuged at $6,000 \times g$ three times for $20 \mathrm{~min}$ each to remove non-encapsulated drug. The encapsulation efficiency was calculated as (New 1989):

Encapsulation efficiency $\%=\frac{[\text { Total drug }]-[\text { Non-encapsulated }]}{[\text { Total drug }]} \times 100$

\section{Liposome morphology by transmission electron microscopy}

The size and morphology of the empty and encapsulated liposomes were studied using transmission electron microscope JEM 1200 (Jeol, LTD, Tokyo, Japan) operating at $120 \mathrm{kV}$. The liposome samples were first diluted (1:10) in distilled water, and $20 \mu \mathrm{l}$ aliquot was applied onto a transmission electron microscopy (TEM) grid. The solution was then left for 1 minute, and the excess was removed from the grid using filter paper. 


\section{Dynamic light scattering}

The mean particle size, size distribution and zeta potential of freshly prepared empty and Dox-encapsulated liposomes were determined by the dynamic light scattering using a particle sizing system (Inc. Sonata Barbara, Calif., USA) at $25^{\circ} \mathrm{C}$ in Trizma buffer ( $\mathrm{pH} 7.4$ ). The results were an average of three separate measurements.

\section{Phase transition temperature (Turbidity method)}

The phase transitions of empty liposomes and liposomes encapsulated with Dox were observed by a spectrophotometer Jenway model 6405 (Barloworld Scientific, Essex, UK) with a jacketed cuvette. The cuvette temperature was monitored by a copper constant thermocouple with $0.1^{\circ} \mathrm{C}$ resolution. The thermocouple was inserted into the cuvette through the tight-fitting Teflon stopper. The cuvette temperature was raised at a rate of $1^{\circ} \mathrm{C} / \mathrm{min}$ from 25 to $50^{\circ} \mathrm{C}$ by circulating water as a thermo controller (Thermomix ${ }^{\circledast}, \mathrm{B}$. Braun Biotech International, Germany). The suspensions were maintained under constant agitation using a rotation speed-controlled paddle Stirrer (Handilab Minor, England) that did not interfere with the light path. Optical densities were recorded at wavelength $550 \mathrm{~nm}$.

\section{In vitro Dox-release study}

The temperature-dependent drug release from a liposome was performed according to the method described in Mills and Needham (2005). Briefly, small $\left(12^{\star} 75 \mathrm{~mm}\right)$ glass test tubes (15 total tubes) were filled with $2 \mathrm{ml}$ of Trizma buffer at room temperature (same buffer as was used during the drug encapsulation procedure). To each test tube, $25 \mu$ l of Dox-encapsulated liposomes was added and mixed gently by swirling. All of the test tubes were placed into a test tube rack, and the entire rack was submerged into a circulating water bath equilibrated to the temperature of interest so that the solution in the tubes was completely submerged below the level of the water, but the tops of the tubes were not in contact with the water.

For the first $9 \mathrm{~min}$, starting at time zero, one test tube was removed every $1 \mathrm{~min}$. Immediately upon removal, the test tubes were placed into an ice water bath to quickly cool them below their phase transitions temperature $T_{m}$ (less than $1 \mathrm{~s}$ ) and stop any subsequent drug release. Drug release at the experimental temperature was monitored over $24 \mathrm{~min}$ with a single tube removed every $4 \mathrm{~min}$. In this manner, every test tube gave a single time point, all the way up to the last 33min time point. When the last test tube was removed, each sample was read separately by placing the tube's entire $2 \mathrm{ml}$ into a quartz cuvette and recording the fluorescence $\left(\mathrm{Fl}_{\mathrm{t}}\right)$ by spectrofluorophotometer ( $\mathrm{RF}_{-}$5301PC, SHIMADZO, Japan) with the excitation and emission wavelengths set to 470 and $590 \mathrm{~nm}$, respectively. Six random samples were then chosen, lysed with $15 \mu \mathrm{l}$ of $10 \%$ Triton X100 and a final fluorescence recording was made. These six readings were then averaged for a final " $100 \%$ Released" value $\left(\mathrm{Fl}_{\mathrm{TX}}\right)$. Percent of drug release was then calculated, where $\mathrm{Fl}_{\mathrm{t} 0}$ was the fluorescence of the zero time point sample

Percent Release $=\left[\left(\mathrm{Fl}_{\mathrm{t}}-\mathrm{Fl}_{\mathrm{t} 0}\right) /\left(\mathrm{Fl}_{\mathrm{TX}}-\mathrm{Fl}_{\mathrm{t} 0}\right)\right]{ }^{\star} 100$

\section{Cell culture and tumor inoculation}

Ehrlich ascites carcinoma cells (obtained from National Cancer Institute "NCI", Cairo University) containing $1 \times 10^{6}$ cells were intraperitoneally (i.p.) injected into female mice. Ascites fluid was collected on the 7 th day after injection. The Ehrlich cells were washed twice and then resuspended in $0.9 \% \mathrm{NaCl}$ $\left(5 \times 10^{6}\right.$ viable cells). Female BALB mice (obtained from the animal house of NCI, with a body weight 22/25 g, 7/8 weeks old) were injected subcutaneously in their right flanks where the tumor was developed in a single and solid form. Tumor growth was monitored post inoculation until the desired volume was about 0.3 to $0.6 \mathrm{~cm}^{3}$. All animal procedures and care were performed using guidelines for the Care and Use of Laboratory Animals (Council 1996) and approved by animal Ethics Committee at Cairo University.

\section{Treatment protocols}

The experiment was run on a total 20 mice. Ten days after tumor cell inoculation, mice were randomly assigned to experimental groups. Mice of group A were treated with free Dox in equivalent to that maximum released from the liposomes ( $1 \mathrm{mg} / \mathrm{kg}$ body weight dose). Mice of group B were treated with liposomes encapsulated by Dox followed by $5 \mathrm{~min}$ localized hyperthermia (HT-5min). Mice of group C were injected with liposomes encapsulated by Dox followed by $30 \mathrm{~min}$ localized hyperthermia (HT-30min). Mice of group D (control group) were neither injected with free Dox nor liposomes. Free Dox or liposomes encapsulated by Dox was injected into the tumor interstitium (IT). Immediately after drug administration, localized hyperthermia treatment was applied either for $5 \mathrm{~min}$ or $30 \mathrm{~min}$ at $42^{\circ} \mathrm{C}$.

For hyperthermia treatment, a thermostat (Thermomix ${ }^{\oplus}, \mathrm{B}$. Braun Biotech International, Germany) controlled circulating water bath with an accuracy of $\pm 0.5^{\circ} \mathrm{C}$ and working temperature range of water bath was $22-100^{\circ} \mathrm{C}$. The set temperature was achieved and stabilized within $10 \mathrm{~min}$ and maintained throughout the experiment. Mice were anesthetized via i.p. injection with thiopental ( $48 \mathrm{mg} / \mathrm{kg}$ ) and were placed on a Perspex tray with longitudinal slits. The tumors were pulled out through the slits in such a way that only the tumors protruded out to the water below the tray, while the animal remained above the tray. Thus the tumors could be heated without af- 
fecting the other parts of the body. A table fan was used to ventilate the air so as to control humidity above the water bath. The intra tumor temperatures at three points i.e. at the base, center and outer periphery of the tumor, were measured using (Wahl TM-410, K-type, USA) needle thermocouple (42 $\left.\pm 0.05^{\circ} \mathrm{C}\right)$. After $24 \mathrm{~h}$ of the treatment, the mice were sacrificed and a small piece of tumor tissues $(n=5)$ from each group used for preparing tumor cells. Tumor cells were released from solid tumor tissue by mechanical disaggregation in $1 \mathrm{ml}$ cold HBSS containing $20 \mathrm{mM}$ EDTA (ethylenediaminetetraacetic acid)/10\% DMSO (dimethylsulfoxide, Qualigens, CPW59) until the tumor tissue was completely dispersed. After that, tumor cells were passed in filters (MiltenyiBiotec) to remove clusters then collected by centrifugation at $1000 \mathrm{rpm}$ for 10 min and resuspended for using in flow-cytometric assay of apoptosis and comet assays.

\section{Flow-cytometry assay}

Apoptotic and necrotic cells were quantified by Annexin V-FITC-Propidiumiodide (PI) double staining, using an Annexin V-FITC apoptosis detection kit according to the method of Van Engeland et al. (1998). Annexin V FITC Conjugate were added to the treated and untreated cells ac-
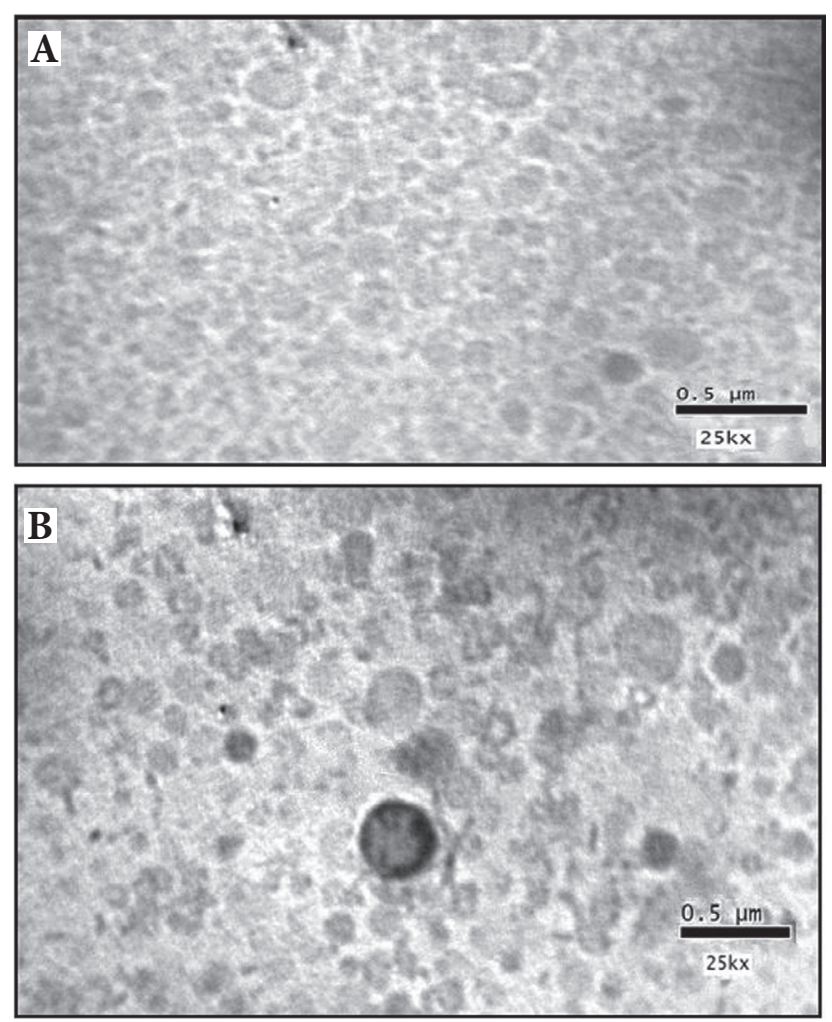

Figure 1. TEM image for empty (A) and doxorubicin-encapsulated (B) liposomes. Scale $=0.5 \mu \mathrm{m}$ (magnification $25 \mathrm{kx}$ ). cording to manufacturer's instructions for $10 \mathrm{~min}$ at room temperature while protected from light. Fluorescence of the cells was read immediately by flow cytometer (NAVIOS Beckman Coulter, USA).

\section{Comet assay (single cell gel electrophoresis)}

Comet assay (single cell gel electrophoresis) is considered as a rapid, simple, visual, and sensitive technique to assess DNA fragmentation typical for toxic DNA damage and early stage of apoptosis (Awara et al. 1998; Møller et al. 2000). The comet assay was performed under alkaline conditions $(\mathrm{pH}>13)$ according to the method developed by Singh et al. (1988) and Tice et al. (2000). Briefly, $5 \mu$ l of treated and untreated cells was mixed with $70 \mu \mathrm{l}$ of $0.7 \%$ low melting point (LMP) agarose (Sigma, A9414). This agarose was prepared in $\mathrm{Ca}^{2+}-\mathrm{Mg}^{2+}$ free PBS (phosphate buffered saline, HiMedia, TS1006) at $37^{\circ} \mathrm{C}$ and placed on a microscope slide, which was already covered with a thin layer of $0.5 \%$ normal melting point (NMP) agarose (HiMedia.RM273). After cooling at $4^{\circ} \mathrm{C}$ for $5 \mathrm{~min}$, slides were covered with a third layer of LMP agarose. After solidification at $4^{\circ} \mathrm{C}$ for $5 \mathrm{~min}$, slides were immersed in freshly prepared cold lysis solution $(2.5 \mathrm{M} \mathrm{NaCl}, 1 \mathrm{mM} \mathrm{Na} 2$ EDTA, $10 \mathrm{mM}$ tris base, $\mathrm{pH} 10$, with $1 \%$ Triton $\mathrm{X}-100$ and $10 \%$ DMSO added just before use) at $4^{\circ} \mathrm{C}$ for at least $1 \mathrm{~h}$. Following lyses, slides were placed in a horizontal gel electrophoresis unit and incubated in fresh alkaline electrophoresis buffer ( $1 \mathrm{mM} \mathrm{Na}_{2}$ EDTA, 300 $\mathrm{mM} \mathrm{NaOH}, \mathrm{pH} 13)$. Electrophoresis was conducted for 30 min at $24 \mathrm{~V}(\sim 0.74 \mathrm{~V} / \mathrm{cm})$ and $300 \mathrm{~mA}$ at $4^{\circ} \mathrm{C}$. Then, the slides were immersed in neutralized buffer (0.4 M Tris- $\mathrm{HCl}, \mathrm{pH} 7.5)$ and gently washed three times for $5 \mathrm{~min}$ at $4^{\circ} \mathrm{C}$. All the above procedures were performed under dimmed light to prevent the occurrence of additional DNA damage. Comets were visualized by $80 \mu \mathrm{l}$, $1 \mathrm{X}$ ethidium bromide staining (SigmaE-8751) and examined at $400 \times$ magnification using a fluorescent microscope. Comet 5 image analysis software developed by Kinetic Imaging, Ltd. (Liverpool, UK) linked to a CCD camera was used to assess the quantitative and qualitative extent of DNA damage in the cells by measuring the length of DNA migration and the percentage of migrated DNA. Finally, the program calculates tail moment and Olive tail moment. In all the samples, 50 cells were analyzed and classified into 5 types (0-4) depending on their olive tail moment. Type 0 represents the cells without visible damage, while cells of type 4 have total degradation of DNA (long, broad tail, poorly visible head of the comet). Types 1, 2, and 3 represent the symptoms of increasing DNA damage. To calculate the extent of DNA damage, three types of the comet: numbers 2,3 , and 4 were selected.

\section{Statistical analysis}

Data were expressed as mean \pm standard deviation. Statistical analysis was performed by one way variance analysis 


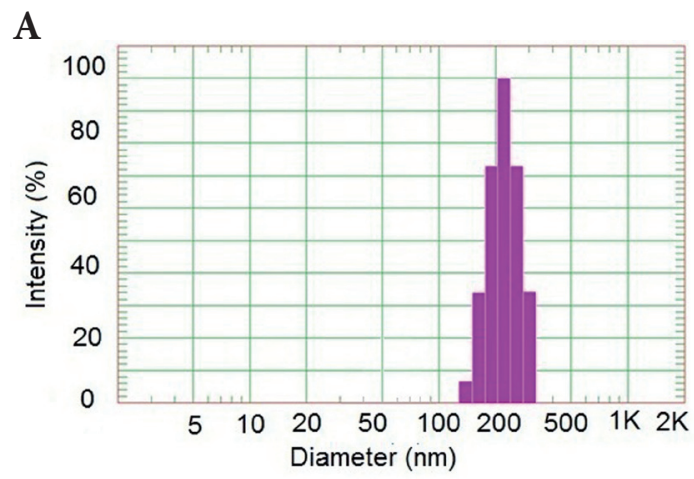

B

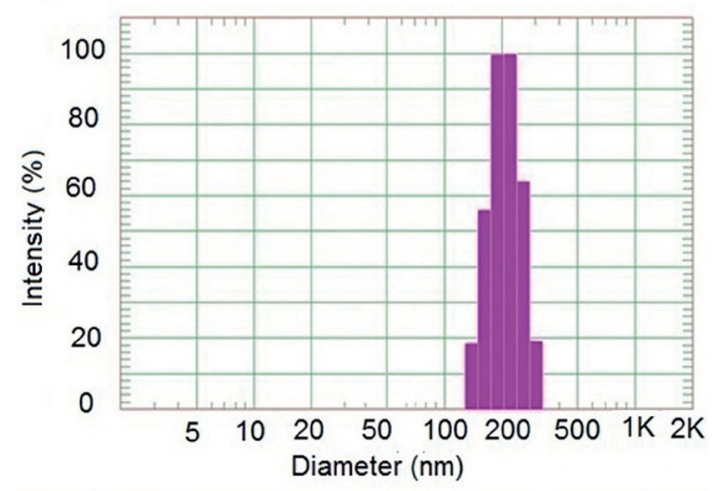

Figure 2. Liposomes size distributions measured by dynamic light scattering (DSL) for empty (A) and doxorubicin-encapsulated (B) liposomes.

ANOVA using SPSS (version 17.0). Difference were considered significant when $p<0.05$.

\section{Results}

The applied preparation method yielded thermosensitive liposomes (DPPC/DSPC and DPPC/DSPC/Dox) with good reproducibility in most tested biophysical parameters independent from lipid composition with about $70.5 \pm$ $5 \%$ encapsulation efficiency. The morphology and size of empty and encapsulated liposomes were examined by TEM
A

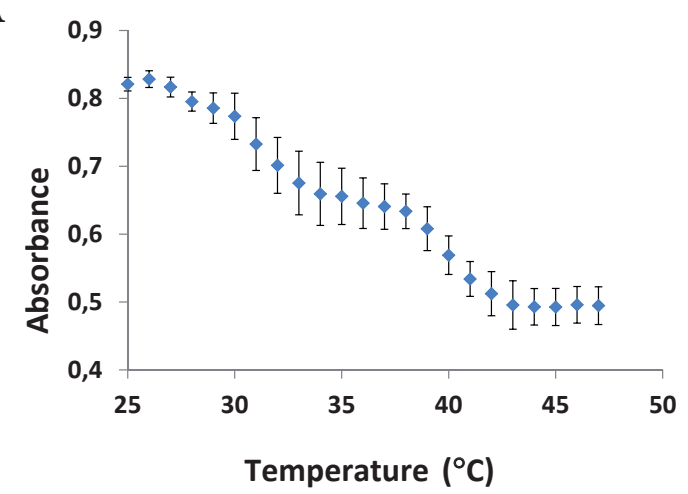

B

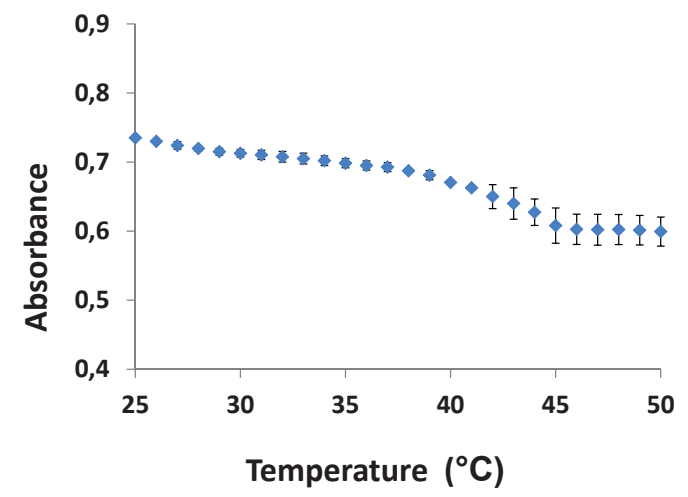

Figure 3. Turbidity profile for empty (A) and doxorubicin-encapsulated (B) liposomes as a function of temperature. The data point represent the mean $\pm \mathrm{SD}(n=3)$.

(Figure 1). TEM images showed well dispersed and not aggregated round shaped empty and encapsulated vesicles had a diameter around $238 \pm 12 \mathrm{~nm}$ and $223 \pm 28 \mathrm{~nm}$, respectively. These results confirmed by dynamic light scattering (DLS) measurement (Figure 2). Figure 2 represents a typical size distribution graphs for both empty and encapsulated liposomes. As shown in this figure, the sizes of empty and encapsulated liposomes were concentrated around $224 \pm$ $30 \mathrm{~nm}$ and $216 \pm 18 \mathrm{~nm}$, respectively, with relatively narrow distribution.

Zeta potential analyzer was used to determine the electrokinetic surface potential for empty and encapsulated liposomes (Table 1) and showed that Dox encapsulation

Table 1. Summarized data obtained for the physicochemical properties for thermosensitive liposomes before and after encapsulation by doxorubicin

\begin{tabular}{|c|c|c|c|c|}
\hline & \multicolumn{2}{|c|}{ Diameter (nm) } & \multirow{2}{*}{$\begin{array}{c}\text { Phase transition } \\
\mathrm{T}_{\mathrm{m}}\left({ }^{\circ} \mathrm{C}\right)\end{array}$} & \multirow{2}{*}{$\begin{array}{l}\text { Zeta potential } \\
\qquad(\mathrm{mV})\end{array}$} \\
\hline & DLS & TEM & & \\
\hline Empty liposome & $224 \pm 30$ & $238 \pm 12$ & $44 \pm 0.5$ & $-38.1 \pm 3.3$ \\
\hline Dox-encapsulated liposome & $216 \pm 18$ & $223 \pm 28$ & $42 \pm 0.6$ & $3.4 \pm 0.9$ \\
\hline
\end{tabular}

The data point represent the mean \pm SD $(n=3)$. DLS, dynamic light scattering; TEM, transmission electron microscopy. 
A

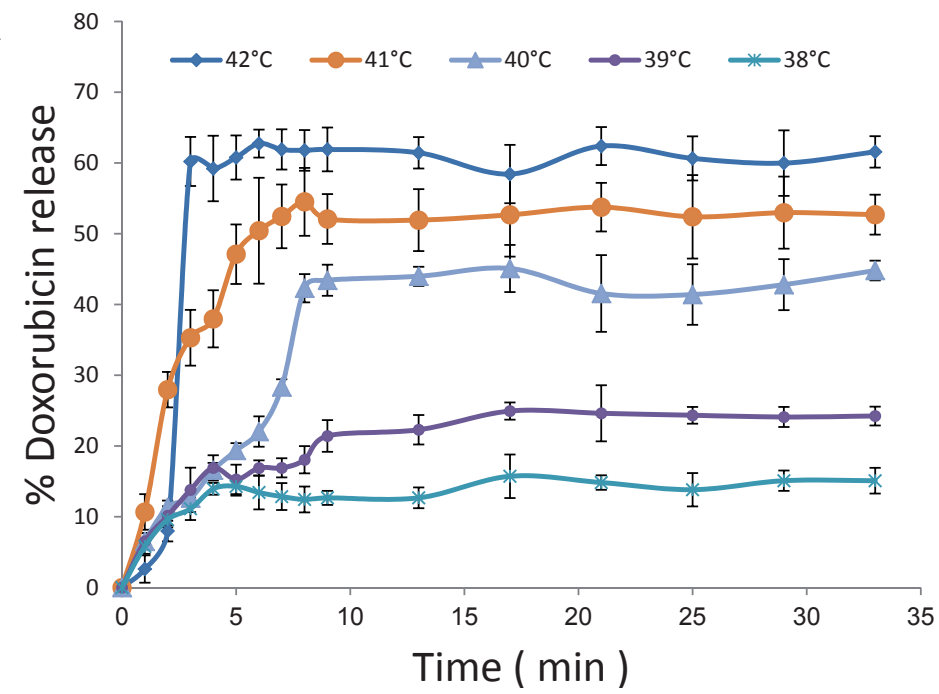

B

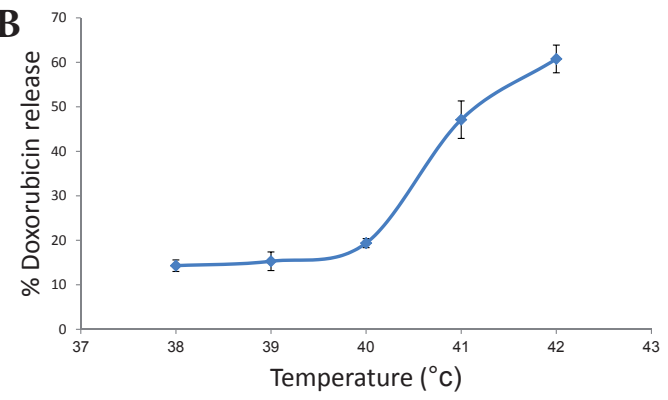

Figure 4. A. Release of doxorubicin from the encapsulated liposomes at $38,39,40,41$ and $42^{\circ} \mathrm{C}$ in trizma buffer ( $\mathrm{pH}$ 7.4). The percentage of doxorubicin released was calculated from the fluorescence intensities which were measured over time. B. Doxorubicin release from liposomes in $5 \mathrm{~min}$ at different temperatures. The data point represent the mean $\pm \mathrm{SD}(n=3)$. increased in zeta potential about10-fold compared to empty liposomes.

Figure 3A shows the temperature-induced variation in the absorbance values at $550 \mathrm{~nm}$ for empty liposomes (DPPC:DSPC, 9:1). As can be seen from the figure, for empty liposomes, the system shows two transitions. A minor transition at $34^{\circ} \mathrm{C}$ and a more abrupt transition at about $44^{\circ} \mathrm{C}$ which corresponds to the pre $\left(\mathrm{T}_{\mathrm{p}}\right)$ and main phase transition $\left(\mathrm{T}_{\mathrm{m}}\right)$, respectively. Figure 3B shows the temperatureinduced variation in the absorbance values at $550 \mathrm{~nm}$ for encapsulated liposomes. As indicated in the figure at Dox encapsulation the pretransition disappears, broadening, and shift to lower temperature of the main phase transition is observed at $42^{\circ} \mathrm{C}$.

A representative set of data from the Dox release measurements is shown in Figure $4 \mathrm{~A}$ as percentage of Dox released versus time in minutes at $38,39,40,41$ and $42^{\circ} \mathrm{C}$. At temperature 38 and $39^{\circ} \mathrm{C}$ the formulation of the liposomes is fairly stable, releasing only $10-20 \%$ over the course of $30 \mathrm{~min}$. Drug release rapidly increases when the liposomes pass through the transition region, with $40,50,60 \%$ of encapsulated contents

Table 2. The percentage of apoptosis and necrosis cells in different treated groups measured by flow cytometry

\begin{tabular}{lcr}
\hline Groups & Apoptosis (\%) & Necrosis (\%) \\
\hline Control & $0.09 \pm 0.01$ & $0.14 \pm 0.02$ \\
Free Dox & $24.69 \pm 3.72$ & $5.29 \pm 0.65$ \\
HT-5min & $23.19 \pm 2.61$ & $8.43 \pm 0.94$ \\
HT-30min & $28.61 \pm 2.07$ & $19.06 \pm 1.79$ \\
\hline
\end{tabular}

The data point represent the mean $\pm \mathrm{SD}(n=5)$. HT- 5 min, mice treated with liposomes encapsulated by doxorubicin followed by $5 \mathrm{~min}$ localized hyperthermia; HT-30min, mice injected with liposomes encapsulated by Dox followed by $30 \mathrm{~min}$ localized hyperthermia. released within $5-10 \mathrm{~min}$ at 40,41 and $42^{\circ} \mathrm{C}$, respectively. Temperature-dependent Dox release profile of thermosensitive liposomes (Figure 4B) showed that the amount of Dox release during 5 min was dramatically influenced by temperature.

Apoptosis was determined by flow cytometry in Ehrlich carcinoma cells that have been stained with FITCannexin V and PI. Percentages of cells in each quadrant in Figure 5 are representative of early apoptosis (LR), necrosis (UR), live cells (LL), and late apoptosis (UL). Figure 5 shows that the percentage of early apoptotic and necrostic cells were dramatically increased after treatment with free Dox or liposomes encapsulated Dox followed by 5 and $30 \mathrm{~min}$ hyperthermia in comparison to the cells of control groups $(p<0.001)$. Treatment with free Dox and liposomes encapsulated Dox followed by 5 min hyperthermia (HT-5min) showed nearly the same values of early apoptotic cells (24.69\% and $23.19 \%$, respectively), while the combination treatment of Dox with hyperthermia for $30 \mathrm{~min}$ (HT-30min) showed $28.61 \%$ of early apoptotic cells. The percentage of necrotic cells significantly markedly appears in HT-30min groups $(p<0.001)$. Table 2 summarizes the percentage of apoptosis and necrosis for each treated groups.

Levels of DNA damage in cells of Ehrlich tumor showed a significant increase $(p<0.001)$ in treated groups compared to control group (Figures 6 and 7). For type (0), the data revealed that about $60 \%$ of Ehrlich tumor cells did not exhibit any DNA damage in control group (D) compared to about 40,38 and $14 \%$ in treated groups A, B and C respectively. Meanwhile in type (4) about 10, 12 and 15\% of Ehrlich tumor cells showed a complete DNA damage in treated groups A, $\mathrm{B}$ and $\mathrm{C}$ respectively, relative to $1 \%$ for control group (D). The total percent of DNA damage in Ehrlich tumor cells 


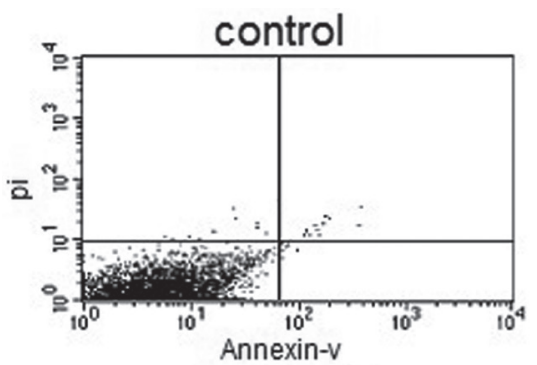

\begin{tabular}{|c|c|}
\hline \multicolumn{2}{|c|}{ Quad \%Gated } \\
\hline UL & 0.11 \\
\hline UR & 0.14 \\
\hline LL & 99.66 \\
\hline LR & 0.09 \\
\hline
\end{tabular}

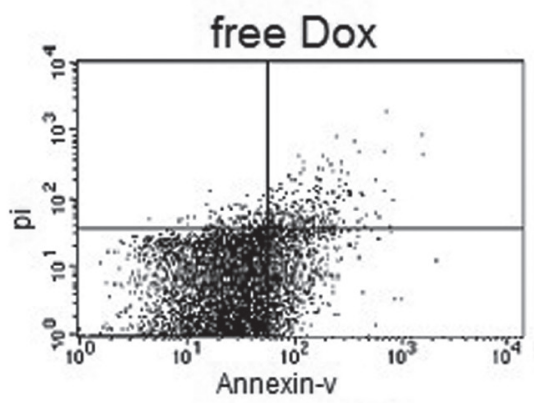

$\begin{array}{ll}\frac{\text { Quad }}{\text { UL }} & \frac{1.51}{1.51} \\ \text { UR } & 5.29 \\ \text { LL } & 68.51 \\ \text { LR } & 24.69\end{array}$

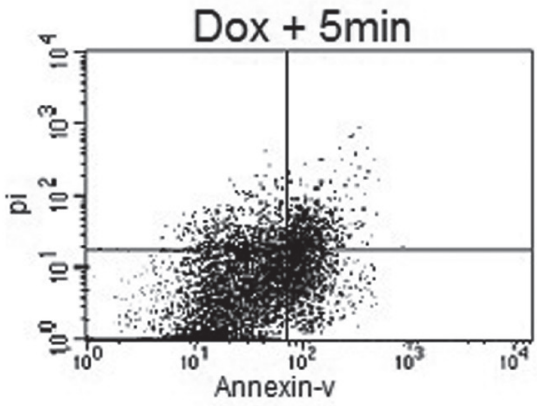

$\begin{array}{ll}\frac{\text { Quad }}{\text { UL }} & \frac{\text { \%ated }}{3.1} \\ \text { UR } & 8.43 \\ \text { LL } & 65.28 \\ \text { LR } & 23.19\end{array}$

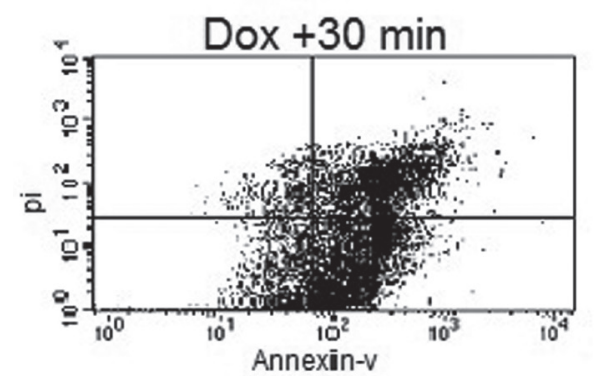

Quad \%Gated

UL 6.14

UR $\quad 19.06$

LL $\quad 46.19$

LR $\quad 28.61$

Figure 5. Apoptosis and necrosis of Ehrlich carcinoma cells analyzed by flow cytometry after different treatments as described before in material and methods. The scatter point in the first quadrant (UR) stood for necrosis cells, that in second quadrant (UL) represented late apoptosis, that in the third quadrant (LL) meant living cells, and the fourth quadrant (LR) early apoptosis cells. Dox, doxorubicin.

represented by types (2, 3 and 4) showed 2.5-, 2- and 3-fold increase for treated groups A, B and C respectively, with respect to control group (D). Also Table 3 showed a significant increase $(p<0.001)$ in comet parameters (tail length, \%DNA in tail and tail moment) for all treated groups compared to the control one.
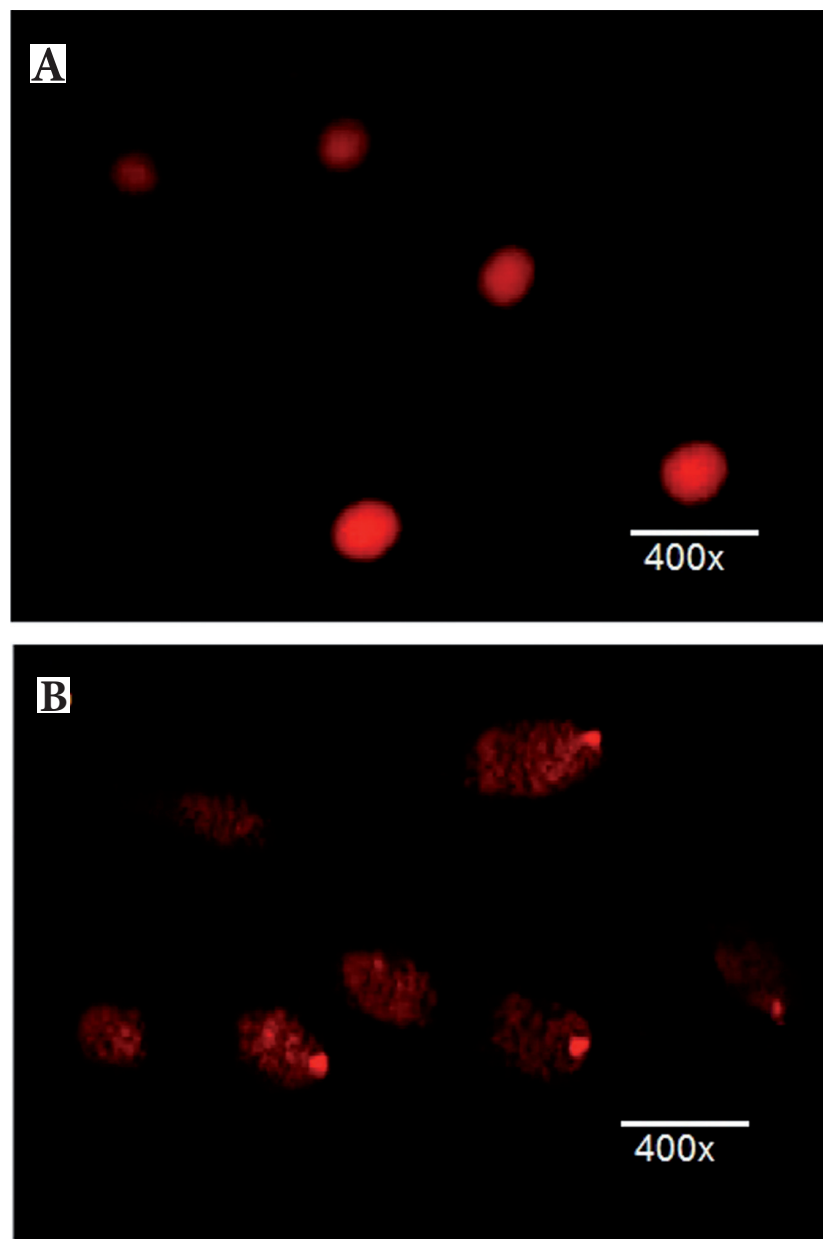

Figure 6. Typical comet images of Ehrlich carcinoma cells for (A) cells without visible DNA damage ( level 0), (B) cells with a major DNA damage (level 4), induced by HT in combination thermosensitive liposomes encapsulated by doxorubicin.

Table 4 shows correlation coefficients between comet parameters and the percentage of apoptosis measured by the flow cytometry. The results showed the \% DNA in tail is in very good correlation with the percentage of apoptosis.

\section{Discussion}

Liposomes are now well recognized for their ability to increase the therapeutic activity and/or reduce the toxicity of selected encapsulated chemotherapeutic agents. Based on the principle that maximum therapeutic effects may only be achieved when tumor cells are subject to maximum drug exposure, it is important to retain two key attributes when optimizing liposomal anti-cancer drug formulations, including: 1) extended liposome circulation lifetime for passive accumulation in tumors, and 2) retention of the encapsulated 


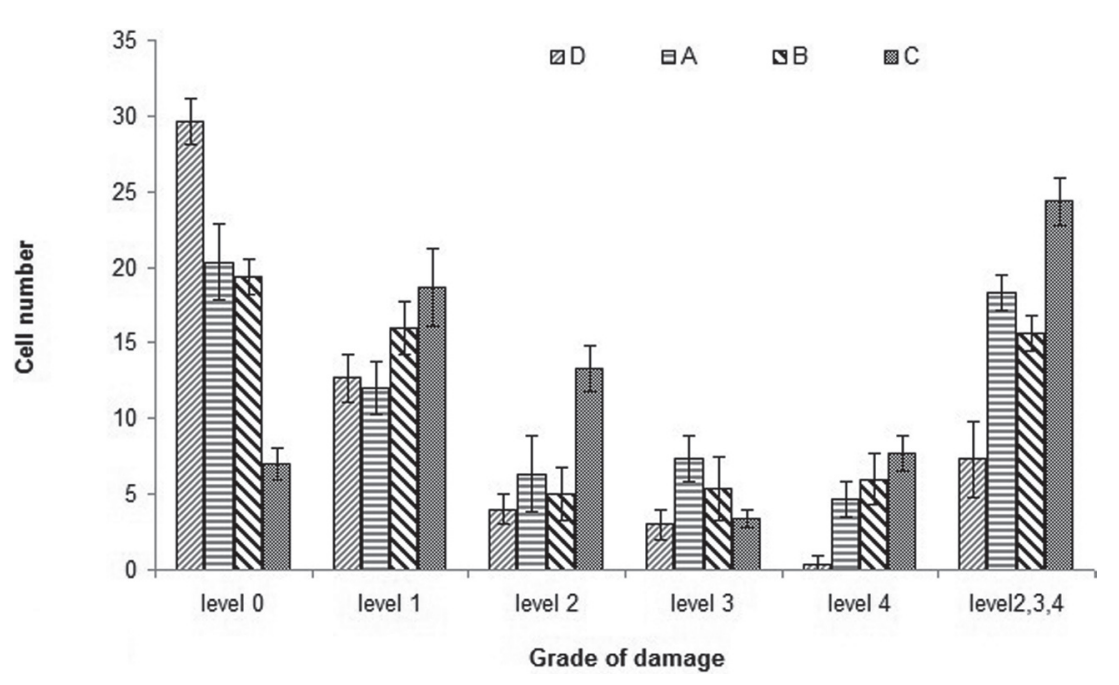

Figure 7. The level of DNA damage in Ehrlich carcinoma cells for mice groups treated with free doxorubicin (group A), HT-5min (group B), HT-30min (group C) and the control one (group D) by comet assay. The data point represent the mean $\pm \mathrm{SD}(n=5$, $p<0.001$ compared to the control group). drug until delivery to the tumor site. Thus, it is necessary to design the liposomal carrier better such that the liposomes can be triggered to release encapsulated contents. Among the various triggers for liposomal content release, the use of heat or hyperthermia has been actively pursued because of several advantages. Hyperthermia can increase tumor blood flow and microvascular permeability, and hyperthermia has been shown to increase the extravasation and the accumulation of liposomes in the locally heated tumor (Kong et al. 2000). Thus, hyperthermia can increase the delivery of liposomes to the tumor and augment the exposure of tumor cells to drug that has been released from localized

Table 3. Comet parameters (tail length, \% DNA in tail and tail moment) for all treated groups

\begin{tabular}{lclc}
\hline Groups & Tail length $(\mathrm{px})$ & \multicolumn{1}{c}{$\%$ DNA } & Tail moment \\
\hline Control & $9.6 \pm 0.76$ & $19.71 \pm 1.75$ & $3.06 \pm 0.28$ \\
Free Dox & $10.11 \pm 0.88$ & $37.54 \pm 5.4$ & $5.18 \pm 0.43$ \\
HT-5 min & $12.35 \pm 0.92$ & $36.68 \pm 2.98$ & $6.29 \pm 0.38$ \\
HT-30 min & $22.6 \pm 1.83$ & $41.75 \pm 2.76$ & $10.8 \pm 0.72$ \\
\hline
\end{tabular}

The data point represent the mean \pm SD $(n=5)$. HT- 5 min, mice treated with liposomes encapsulated by doxorubicin followed by 5 min localized hyperthermia; HT-30min, mice injected with liposomes encapsulated by Dox followed by $30 \mathrm{~min}$ localized hyperthermia. $p<0.001$ compared to the control group, $1 \mathrm{px}=0.24 \mu \mathrm{m}$.

Table 4. Correction coefficient between comet assay parameters and $\%$ of apoptosis

\begin{tabular}{cccc}
\hline & Tail moment & Tail Length & $\%$ DNA in Tail \\
\hline$\%$ apoptosis & $0.678^{*}$ & 0.535 & $0.982^{* *}$ \\
\hline${ }^{*} p<0.05$ Pearson's correlation; ${ }^{* *} p<0.01$ Pearson's correlation.
\end{tabular}

liposomes. In the design of thermosensitive liposomes, it is necessary to choose a phospholipid that has a phase transition temperature $\left(\mathrm{T}_{\mathrm{c}}\right)$ in the temperature range of clinically attainable local hyperthermia $\left(41-42^{\circ} \mathrm{C}\right)$ to allow triggered drug release. Dipalmitoylphosphatidylcholine (DPPC) which has a Tc of $41.5^{\circ} \mathrm{C}$ has been the lipid of choice as the primary constituent of thermosensitive liposomes. In early studies, other lipids such as dipalmitoylphosphatidylglycerol (DPPG) and distearoylphosphatidylcholine (DSPC) have also been added in various ratios to modify the drug release temperature to the desired range (Yatvin et al. 1978).

The morphology and size of empty and encapsulated liposomes were examined by TEM (Figure 1). The mean particle diameter was estimated to be $238 \pm 12 \mathrm{~nm}$ for empty liposomes while Dox encapsulated liposomes showed a mean particle diameter of $223 \pm 28 \mathrm{~nm}$ which is not statistically significant different from that of the empty liposomes. These results are confirmed by DLS measurement (Figure 2). For instance, the optimal size range for parenteral administration is between 70 and $400 \mathrm{~nm}$. Within this size range, liposomes favor the accumulation of drugs into certain target organs such as liver, spleen, and bone marrow. Besides, they also have a good stability in the blood, thus displaying predictable drug-release rates.

Zeta potential is a measure of the surface electrical charge of particles, and has often been used to characterize colloidal drug delivery systems. The magnitude of the zeta potential gives an indication of the potential stability of the colloidal system. As the zeta potential increases, repulsion between particles will be greater, leading to a more stable colloidal dispersion. If all particles in suspension have a large negative or positive zeta potential then they will tend to repel each other and there will be no tendency for the particles to come together (Paolino et al. 2006). In particles with low zeta potential values, there is only little repulsion force and 
the particles will eventually aggregate, resulting in dispersion instability. Information on the overall charge of Doxencapsulated liposomes by zeta potential measurements can speed up the development of liposomes with specific, prolonged and controlled release.

DPPC liposomes showed a negative zeta potential, in agreement with the observations of previous studies (Makino et al. 1991). It is clear from Table 1 that the encapsulation of liposomes by Dox shifted the zeta potential from negative to positive values. The increase of zeta potential can be attributed to more cationic Dox adsorbed to the liposomal surface, since doxorubicin was a kind of weak base.

The turbidity technique at visible range is one of the spectroscopic techniques which provide valuable information about membrane phase transition temperature and membrane order (Eker et al. 1999; Severcan et al. 2000; Mady and Darwish 2010). Lipid turbidity study has been previously applied to membrane research by others (Severcan et al. 1995; Stillwell and Wassall 1990). It is known that when temperature is increased, phosphatidylcholines undergo phase transitions from the lamellar gel phase $L \beta$ ' to the ripple phase $\mathrm{P} \beta$, and further to the fluid lamellar phase $\mathrm{L} \alpha$. However, the phase transition of phospholipids from the gel to the liquid crystalline phase causes a decrease in turbidity. This is mainly due to the changes that occur in the refractive index of the lipids, as a consequence of changes in the lipid density during melting (Yi and MacDonald 1973). Turbidity measurements provide a useful tool in studying the effects of additives such as ions, peptides, proteins, drugs etc. on the size, structure, aggregation and fusion process of lipid vesicles and such studies would provide a better understanding of vesicles (Eker et al. 1999).

Figure 3 represents the variation of the absorbance at $550 \mathrm{~nm}$ as a function of temperature for mixed liposomes and Dox-encapsulated mixed liposomes (DPPC:DSPC, 9:1). As seen from the figure, for pure mixed liposomes, the absorbance values decreased as a function of increasing temperature and show two transitions: a pre-transition is observed at nearly $34^{\circ} \mathrm{C}$ and a main transition is seen around $44^{\circ} \mathrm{C}$ of DPPC/DSPC. These temperatures are very close to the values reported by calorimetric (Papahadjopoulos et al. 1974) and turbidity studies (Stillwell and Wassall 1990; Severcan et al. 2000).

Turbidity studies revealed that loading of DPPC/DSPC liposomes by Dox led to the disappearance of pre-transition and lowering of the main transition temperature by nearly $2^{\circ} \mathrm{C}$ relative to the control. The results indicated that the Dox interact strongly with DPPC/DSPC vesicles and cause their melting points to be decreased. This might be due to the structural modifications and interactions between DPPC/ DSPC molecules and Dox within the bilayer.

Heat sensitive liposome technology is a potential method to produce triggered systems for controlled contents deliv- ery. The temperature required for gel-to-liquid crystalline phase transition in the liposomes can be adjusted by lipid composition. This property has been used for example in the cancer treatments, where the slightly higher temperature in the tumor triggers the drug release from the liposomes with a phase transition below $41^{\circ} \mathrm{C}$ (Lindner et al. 2004).

The release rate of Dox is an important factor since a slow release is necessary in order to decrease the side effects of doxorubicin and improve its therapeutic index (Gabizon 2002). A slow release rate cans also contribute to the accumulation of the drug in the tumor (Charrois and Allen 2004).

In the design of thermosensitive liposomes, it is necessary to choose a phospholipid that has a phase transition temperature $\left(T_{c}\right)$ in the temperature range of clinically attainable local hyperthermia $\left(41-42^{\circ} \mathrm{C}\right)$. For liposomes composed of DPPC alone, the rates of release and the amount released are relatively small. However, they can be increased by supplementing the DPPC bilayer with other lipids such as DSPC $\left(\mathrm{T}_{\mathrm{c}}=54.9^{\circ} \mathrm{C}\right)$. For the liposomes obtained from mixtures DPPC:DSPC (9:1 molar ratio), the $T_{c}$ is between $43-45^{\circ} \mathrm{C}$ (Needham and Dewhirst 2001; Papagiannaros et al. 2006).

The results of the in vitro Dox release studies at various temperatures has indicated that the maximum release $(60 \%)$ occurred at $42^{\circ} \mathrm{C}$ and less than $10 \%$ release occurred at temperatures less than $38^{\circ} \mathrm{C}$. This may be because of the phase transition temperature of the phospholipid vesicles, which was found to be $42^{\circ} \mathrm{C}$, which was in close correspondence to the reported values (Mabrey 1981).

The combination of local hyperthermia with Dox encapsulated nano scale thermosensitive liposomes to trigger drug release is an attractive approach to enhance their chemotherapeutic activity, reduce the dose required for treatment and decrease the systemic circulation of Dox. The mechanism of chemotherapeutic action of Dox on cancer cells is through DNA intercalation and topoisomerase $\Pi$ enzyme inhibition (Lee et al. 2002).

Through these two actions, doxorubicin can disrupt cellular processes involving DNA such as synthesis and transcription, leading to cell death (Kim et al. 2010).

Hyperthermia induces two distinct pathways for the cells death process: apoptosis and necrosis. Apoptosis is a mechanism of DNA damage manifests by means of cell cycle arrest. Necrosis is the other form of cell death, where the protein become structurally unstable and may even unfold leading to loss of function of the affected proteins and to intracellular accumulation of aggregates (Issels 2008).

The present data suggest that flow cytometric assay of apoptosis and alkaline comet assay have the potential of being a surrogate endpoint for cell death and DNA damage that produced by local hyperthermia and Dox encapsulated nanoscale liposomes. The percentage of cell death and DNA breaks may be able to predict the efficiency of treatment. 
The current study had revealed that local administration of low dose Dox loaded thermosensitive nanoscale liposomes followed by local hyperthermia disrupts the integrity and the amount of intact DNA. Comet results emphasized the increase in the number of cells with damaged DNA levels (2, 3 and 4) (Figure 7 and Table 3 in groups A, B and C); this damage might be attributed to the intercalation of Dox with DNA. Such observed DNA damage is in agreement with previous studies (L'Ecuyer et al. 2006; Cutts et al. 1996) who reported that Dox rapidly localizes to the nucleus in tumor cells, related to its high affinity for DNA. The drug intercalates rapidly in the DNA strand at specific sequences. Specific DNA-binding proteins, including transcription factors, may thereby be denied access to their usual binding sites by these adducts, potentially inhibiting transcription of specific genes. Moreover, another study (Blasiak et al. 2003) suggested that free radicals produced by anthracyclines induce DNA single strand breaks, alkali labile sites and oxidized DNA bases.

The apoptotic and necrotic potential of bimodality treatment increased significantly in group (C) (Figure 5) such results are consistent with Decaudin et al. (1997) and Gamen et al. (2000) who reported that Dox induces cancer cell apoptosis via the mitochondrial pathway which was found to depend on the expression of proapoptotic Box gene as well. Box expression can induce the mitochondrial membrane to emerge pores and reduce the mitochondrial potential, ultimately leading to the release of cytochrome $\mathrm{c}$ to the cytoplasm. Moreover hyperthermia induces necrosis via mitochondrial swelling followed by rupture of the plasma membrane and release of cytoplasmic constituents, which include protealytic enzymes (Issels 2008). Moreover, Asanami et al. (2001), Hintzsche et al. (2012), Nadin et al. (2012) and Speit and Schütz (2013) had results which indicate that apoptotic cell death is not the predominant biological effect of hyperthermia. Hyperthermia-induced DNA damage has the potential to induce mutations, at least at the chromosomal level. The present study confirms the last report on induction of apoptotic cells and DNA damage by hyperthermia (Figure 5 and Table 3 group C).

An additional effect of hyperthermia combined with chemotherapy is the recently discovered effect on DNArepair inhibition (Kampinga and Dikomey 2001; Krawczyk et al. 2011; Eppink et al. 2012). Radiation and chemotherapy action is often based on induction of DNA double-strand breaks (DSB). Under normal circumstances, effective DNA repair mechanisms are executed to protect against abnormal DNA rearrangements.

Two main mechanisms involved in DSB repair are homologous recombination (HR) and non-homologous end joining. HR was demonstrated to be inhibited by hyperthermia through degradation of breast cancer suppressor genes (BRCA2) (Kampinga and Dikomey 2001; Krawczyk et al. 2011; Eppink et al. 2012). As a result innately HR-proficient
BRCA2-positive tumors became sensitive to polymerase inhibitors (PARP-1) through hyperthermia. In this approach, hyperthermia had no direct effect on DNA damage, but rather on the proteins involved in DNA repair, replication or chromosomal segregations (Krawczyk et al. 2011).

\section{Conclusion}

These results show clearly that Dox encapsulated in nano scales thermosensitive liposomes in combination with hyperthermia, causes a marked improvement in therapeutic efficiency by enhancement tumor cell death and DNA damage.

\section{References}

Asanami S., Shimono K., Kaneda S. (2001): Effect of temperature on the frequency of chromosome aberrations and micronuclei in cultured Chinese hamster cells. J. Toxicol. Sci. 26, 323-326 http://dx.doi.org/10.2131/jts.26.323

Awara W. M., El-Nabi S. H., El-Gohary M. (1998): Assessment of vinyl chloride-induced DNA damage in lymphocytes of plastic industry workers using a single-cell gel electrophoresis technique. Toxicol. 128, 9-16 http://dx.doi.org/10.1016/S0300-483X(98)00008-0

Blasiak J., Widera K., Pertynski T. (2003): Hyperthermia can differentially modulate the repair of doxorubicin-damaged DNA in normal and cancer cells. Acta Biochim. Pol. 50, 191-196

Charrois G. J., Allen T. M. (2004): Drug release rate influences the pharmacokinetics, biodistribution, therapeutic activity, and toxicity of pegylated liposomal doxorubicin formulations in murine breast cancer. Biochim. Biophys. Acta Biomem. 1663, 167-177 http://dx.doi.org/10.1016/j.bbamem.2004.03.006

Chiu G. N., Abraham S. A., Ickenstein L. M., Ng R., Karlsson G., Edwards K., Bally M. B. (2005): Encapsulation of doxorubicin into thermosensitive liposomes via complexation with the transition metal manganese. J. Control Release. 104, 271-288 http://dx.doi.org/10.1016/j.jconrel.2005.02.009

Cummings J., Anderson L., Willmott N., Smyth J. F. (1991): The molecular pharmacology of doxorubicin in vivo. Eur. J. Cancer. $27,532-535$ http://dx.doi.org/10.1016/0277-5379(91)90209-V

Cutts S. M., Parsons P. G., Sturm R. A., Phillips D. R. (1996): Adriamycin-induced DNA adducts inhibit the DNA interactions of transcription factors and RNA polymerase. J. Biol. Chem. 271, 5422-5429

http://dx.doi.org/10.1074/jbc.271.10.5422

Decaudin D., Geley S., Hirsch T., Castedo M., Marchetti P., Macho A., Kroemer G. (1997): Bcl-2 and Bcl-XL antagonize the mitochondrial dysfunction preceding nuclear apoptosis induced by chemotherapeutic agents. Cancer Res. 57, 62-67

Dewhirst M. W., Prosnitz L., Thrall D., Prescott D., Clegg S., Charles C., LaRue S. (1997): Hyperthermic treatment of malignant diseases: current status and a view toward the future. Semin. Oncol. 24, 616-625 
Eker F., Durmus H. O., Akinoglu B. G., Severcan F. (1999): Application of turbidity technique on peptide-lipid and drug-lipid interactions. J. Mol. Struct. 482, 693-697 http://dx.doi.org/10.1016/S0022-2860(98)00690-5

Eppink B., Krawczyk P. M., Stap J., Kanaar R. (2012): Hyperthermiainduced DNA repair deficiency suggests novel therapeutic anti-cancer strategies. Int. J. Hyperthermia 28, 509-517 http://dx.doi.org/10.3109/02656736.2012.695427

Gabizon A. A. (2002): Liposomal drug carrier systems in cancer chemotherapy: current status and future prospects. J. Drug Target. 10, 535-538 http://dx.doi.org/10.1080/1061186021000043061

Gamen S., Anel A., Perez-Galan P., Lasierra P., Johnson D. (2000): Doxorubicin treatment activates a Z-VAD-sensitive caspase, which causes deltapsim loss, caspase- 9 activity, and apoptosis in Jurkat cells. Exp. Cell Res. 258, 223-235 http://dx.doi.org/10.1006/excr.2000.4924

Hahn G. M., Braun J., Har-Kedar I. (1975): Thermochemotherapy: synergism between hyperthermia (42-43 degrees) and adriamycin (of bleomycin) in mammalian cell inactivation. Proc. Natl. Acad. Sci. 72, 937-940 http://dx.doi.org/10.1073/pnas.72.3.937

Hincu L., Lupuleasa D., Andries A. (2007): Formulation and characterization of topical liposome gel bearing piroxicam. Farmacia 55, 404-415

Hintzsche H., Riese T., Stopper H. (2012): Hyperthermia-induced micronucleus formation in a human keratinocyte cell line. Mutat. Res. 738, 71-74 http://dx.doi.org/10.1016/j.mrfmmm.2012.08.004

Issels R. D. (2008): Hyperthermia adds to chemotherapy. Eur. J. Cancer. 44, 2546-2554 http://dx.doi.org/10.1016/j.ejca.2008.07.038

Kampinga H. H., Dikomey E. (2001). Hyperthermic radiosensitization: mode of action and clinical relevance. Int. J. Radiat. Biol. 77, 399-408 http://dx.doi.org/10.1080/09553000010024687

Kim D., Hoory T., Monie A., Wu A., Hsueh W. T., Pai S. I., Hung C. F. (2010): Delivery of chemotherapeutic agents using drugloaded irradiated tumor cells to treat murine ovarian tumors. J. Biomed. Sci. 17, 61 http://dx.doi.org/10.1186/1423-0127-17-61

Kong G., Braun R. D., Dewhirst M. W. (2000): Hyperthermia enables tumor-specific nanoparticle delivery: effect of particle size. Cancer Res. 60, 4440-4445

Krawczyk P.M., Eppink B., Essers J. (2011): Mild hyperthermia inhibits homologous recombination, induces BRCA2 degradation, and sensitizes cancer cells to poly (ADP-ribose) polymerase-1 inhibition. Proc. Natl. Acad. Sci. 108, 9851- 9856 http://dx.doi.org/10.1073/pnas.1101053108

L'Ecuyer T., Sanjeev S., Thomas R., Novak R., Das L., Campbell W., Vander Heide R. (2006): DNA damage is an early event in doxorubicin-induced cardiac myocyte death. Am. J. Physiol. Heart Circ. Physiol. 291, H1273-1280 http://dx.doi.org/10.1152/ajpheart.00738.2005

Lee S., Baek M., Kim H. Y., Ha J. H., Jeoung D. I. (2002): Mechanism of doxorubicin-induced cell death and expression profile analysis. Biotechnol. Lett. 24, 1147-1151 http://dx.doi.org/10.1023/A:1016174800956
Lindner L. H., Eichhorn M. E., Eibl H., Teichert N., Schmitt-Sody M., Issels R. D., Dellian M. (2004): Novel temperature-sensitive liposomes with prolonged circulation time. Clin. Cancer Res. 10, 2168-2178 http://dx.doi.org/10.1158/1078-0432.CCR-03-0035

Mabrey S. (1981): From physical structure to therapeutic applications. In: Liposomes. (Ed. C. G. Knight), pp. 105-138, Elsevier, Amsterdam

Mady M. M., Darwish M. M. (2010): Effect of chitosan coating on the characteristics of DPPC liposomes. J. Adv. Res. 1, 187-191 http://dx.doi.org/10.1016/j.jare.2010.05.008

Makino K., Yamada T., Kimura M., Oka T., Ohshima H., Kondo T. (1991): Temperature-and ionic strength-induced conformational changes in the lipid head group region of liposomes as suggested by zeta potential data. Biophys. Chem. 41, 175-183 http://dx.doi.org/10.1016/0301-4622(91)80017-L

Mayer L. D., Tai L. C., Bally M. B., Mitilenes G. N., Ginsberg R. S., Cullis P. R. (1990): Characterization of liposomal systems containing doxorubicin entrapped in response to $\mathrm{pH}$ gradients. Biochim. Biophys. Acta Biomem. 1025, 143-151 http://dx.doi.org/10.1016/0005-2736(90)90091-2

Mills J. K., Needham D. (2005): Lysolipid incorporation in dipalmitoylphosphatidylcholine bilayer membranes enhances the ion permeability and drug release rates at the membrane phase transition. Biochim. Biophys. Acta Biomem. 1716, 77-96 http://dx.doi.org/10.1016/j.bbamem.2005.08.007

Møller P., Knudsen L. E., Loft S., Wallin H. (2000): The comet assay as a rapid test in biomonitoring occupational exposure to DNA-damaging agents and effect of confounding factors. Cancer Epidemiol. Biomarkers Prev. 9, 1005-1015

Nadin S. B., Cuello-Carrión F. D., Sottile M. L., Ciocca D. R., Vargas-Roig L. M. (2012): Effects of hyperthermia on Hsp27 (HSPB1), Hsp72 (HSPA1A) and DNA repair proteins hMLH1 and hMSH2 in human colorectal cancer hMLH1-deficient and hMLH1-proficient cell lines. Int. J. Hyperthermia 28, 191-201 http://dx.doi.org/10.3109/02656736.2011.638962

Needham, D., Dewhirst M. W. (2001): The development and testing of a new temperature-sensitive drug delivery system for the treatment of solid tumors. Adv. Drug Deliv. Rev. 53, 285-305 http://dx.doi.org/10.1016/S0169-409X(01)00233-2

New R. C. R. (1989): Liposomes: A practical approach. IRL Press, pp. 33-103, Oxford, UK

Paolino D., Fresta M., Sinha P., Ferrari M. (2006): Drug delivery systems. In: Encyclopedia of Medical Devices and Instrumentation. (2nd edition), (Ed. J. G. Webester), pp. 437-495, John Wiley and Sons, New Jersey http://dx.doi.org/10.1002/0471732877.emd274

Papagiannaros A., Hatziantoniou S., Dimas K., Papaioannou G. T., Demetzos C. (2006): A liposomal formulation of doxorubicin, composed of hexadecylphosphocholine (HePC): physicochemical characterization and cytotoxic activity against human cancer cell lines. Biomed. Pharmacother. 60, 36-42 http://dx.doi.org/10.1016/j.biopha.2005.09.001

Papahadjopoulos D., Poste G., Schaeffer B. E., Vail W. J. (1974): Membrane fusion and molecular segregation in phospholipid vesicles. Biochim. Biophys. Acta Biomem. 352, 10-28 http://dx.doi.org/10.1016/0005-2736(74)90175-8 
Porfire A. S., Parvu A. E., Daicoviciu D., Leucuţa S. E. (2009): Evaluation of antiinflamatory activity of liposome encapsulated superoxide dismutase in rats peritonitis. Farmacia 57, 412-423

Sadzuka Y., Nakade A., Tsuruda T., Sonobe T. (2003): Study on the characterization of mixed polyethyleneglycol modified liposomes containing doxorubicin. J. Control Release 91, 271-280 http://dx.doi.org/10.1016/S0168-3659(03)00248-7

Severcan F., Kazanci N., Baykal Ü., Süzer Ş. (1995): IR and turbidity studies of vitamin E-cholesterol-phospholipid membrane interactions. Biosci. Rep. 15, 221-229 http://dx.doi.org/10.1007/BF01540456

Severcan F., Okan Durmus H., Eker F., Akinoglu B. G., Haris P. I. (2000): Vitamin D2 modulates melittin membrane interactions. Talanta. 53, 205-211 http://dx.doi.org/10.1016/S0039-9140(00)00453-7

Singh N. P., McCoy M. T., Tice R. R., Schneider E. L. (1988): A simple technique for quantitation of low levels of DNA damage in individual cells. Exp. Cell Res. 175, 184-191 http://dx.doi.org/10.1016/0014-4827(88)90265-0

Speit G., Schütz P. (2013): Hyperthermia-induced genotoxic effects in human A549 cells. Mutat. Res. 747, 1-5 http://dx.doi.org/10.1016/j.mrfmmm.2013.04.008

Stillwell W., Wassall S. R. (1990): Interactions of retinoids with phospholipid membranes: Optical spectroscopy. Methods Enzymol. 189, 373-382 http://dx.doi.org/10.1016/0076-6879(90)89311-5

Tagami T., Ernsting M. J., Li S. D. (2011): Efficient tumor regression by a single and low dose treatment with a novel and enhanced formulation of thermosensitive liposomal doxorubicin. J. Control Release 152, 303-309 http://dx.doi.org/10.1016/j.jconrel.2011.02.009

Tice R. R., Agurell E., Anderson D., Burlinson B., Hartmann A., Kobayashi H., Sasaki Y. F. (2000): Single cell gel/comet assay: guidelines for in vitro and in vivo genetic toxicology testing. Environ. Mol. Mutagen 35, 206-221 http://dx.doi.org/10.1002/(SICI)1098-2280(2000)35:3<206::AID-EM8>3.0.CO;2-J

Van Engeland M., Nieland L. J., Ramaekers F. C., Schutte B., Reutelingsperger C. P. (1998): Annexin V-affinity assay: a review on an apoptosis detection system based on phosphatidylserine exposure. Cytometry 31, 1-9 http://dx.doi.org/10.1002/(SICI)1097-0320(19980101)31:1<1::AID-CYTO1>3.0.CO;2-R

Wells J., Sen A., Hui S. W. (2003): Localized delivery to CT-26 tumors in mice using thermosensitive liposomes. Int. J. Pharm. 261, 105-114 http://dx.doi.org/10.1016/S0378-5173(03)00290-4

Yatvin M. B., Weinstein J. N., Dennis W. H., Blumenthal R. (1978): Design of liposomes for enhanced local release of drugs by hyperthermia. Science. 202, 1290-1293 http://dx.doi.org/10.1126/science.364652

Yi P. N., MacDonald R. C. (1973): Temperature dependence of optical properties of aqueous dispersions of phosphatidylcholine. Chem. Phys. Lipids 11, 114-134 http://dx.doi.org/10.1016/0009-3084(73)90029-7

Received: October 28, 2015

Final version accepted: January 15, 2016

First published online: May 13, 2016 